\title{
Design and Construction of a Speed Bump Power Generator
}

\author{
*Iyen, C. ${ }^{1}$, Anyiin P., Umar, I. ${ }^{2}$, Jaafaru, S. ${ }^{3}$, Wansah, J.F. ${ }^{1}$, Iseh, A. ${ }^{1}$, Akeredolu, B. ${ }^{1}$ \\ ${ }^{I}$ Department of Pure and Applied Physics, Federal University Wukari, Taraba State \\ ${ }^{2}$ Department of Physics, Nasarawa State University, Keffi, Nasarawa State \\ ${ }^{3}$ Shedda Science and Technology Complex (SHESTCO), Gwagwalada, Abuja.
}

*Corresponding Author: Iyen, C, Department of Pure and Applied Physics, Federal University Wukari, Taraba State, Nigeria

\begin{abstract}
Designing energy recovery systems that are pollution free has become a significant goal within the research community. One of numerous systems that have been proposed is Speed Bump Power Generator (SBPG) system that produces electrical power by utilizing the movements of commuting vehicles on highways, boulevards, and streets. When vehicles pass over a SBPG system, the system translates vertically. Consequently, a kinetic energy is produced and transferred into electrical power. In this project, an experimental analysis is performed on the rack-and-pinion system. Results show that electrical power of upto $1.9 \mathrm{kw}$ can be generated from the designed system.
\end{abstract}

Keywords: Speed bumps, Power, energy recovery, SBPG, kinetic energy

\section{INTRODUCTION}

In the recent times, renewable energy and energy return are thought to be the smartest methods to lessen the monetary and environmental setbacks of the optimal utilization of fossil fuels. (Shi and Yin 2012, Panwar et al., 2011, Solangi et al., 2011 and Joselin et al., 2007)

The speed bump is a speed reducing feature design to slow off traffic or reduce their speed through vertical deflection mechanism. A speed bump is a mechanism with a plain piece installed on the roadway at a gradient and the heights ranging between 3 and 4 inches $(7.6$ and $10 \mathrm{~cm})$. The depth of the mechanism buried is approximately 1 foot $(30 \mathrm{~cm})$ contrasting with the width approximately 10 to 14 feet $(3.0$ to $4.3 \mathrm{~m})$. It can be constructed of various sizes and can be installed on a road, adapting pairs of either four foot or six foot devices separated each of the either side of the road with the lowest gradient facing the coming traffic and connected across the entire road surface. The speed bumps was utilized around the world and can be regarded as one of the road safety features to alert the road users on the speed limit where vehicle speeds are statutorily mandated to be at predetermine low speed, usually $40 \mathrm{~km} / \mathrm{h}(25 \mathrm{mph})$, (5 to $10 \mathrm{mph}$ ) in residential areas, school crossing or car parks. These devices may be designed to perform dual functions, beside for the road safety it can also produce some amount of electric current from generator concept of design and can be utilized for lighting of its caution beacon where the device is placed. Most of all, it's an environment friendly device (Schlabbachet al; 1997). Electric generator is a device that converts mechanical energy obtained from an external source into electrical energy as the output (Rozenblat, 2008).

The present study of this research is to design and construct a prototype speed bump power generator and as well as conduct an experimental study on the system performance.

\section{Materials AND MethodS}

\section{Materials}

Gear

A rotating machine part having cut teeth, or cogs, which mesh with another toothed part in order to transmit torque. Two or more gears working in tandem are called a transmission and can produce a mechanical advantage through a gear ratio and thus may be considered a simple machine. Geared devices can change the speed, torque, and direction of a power source (deVick, H). Figure 3.3 shows the gear. For this project, only the rack and pinion gear are used. 


\section{Compression Springs}

A spring is an elastic object used to store mechanical energy when a spring is compressed or stretched from its resting position, it exerts an opposing force approximately proportional to its change in length (this approximation breaks down for larger deflections).

\section{Light Emitter Diode/Multimeter}

A light-emitting diode (LED) is a two-lead semiconductor light source. It is a $\mathrm{p}-\mathrm{n}$ junction diode that emits light when activated (the American heritage science dictionary 2005). When a suitable voltage is applied to the leads, electrons are able to recombine with electron holes within the device, releasing energy in the form of photons. This effect is called electroluminescence. Whereas, A multimeter or a multitester, also known as a VOM (volt-ohm-milliammeter), is an electronic measuring instrument that combines several measurement functions in one unit. A typical multimeter can measure voltage, current, and resistance.

\section{Digital Multimeter}

\section{Generator}

An electric generator is a device that converts motive power (mechanical power) into electrical power for use in an external circuit.

\section{A Dynamo Attached to a Pinion Gear}

\section{Sprocket and Chain}

A sprocket is a profiled wheel with teeth, or cogs that mesh with a chain to transmit rotary or torque. Sprockets are one common way to transmit power and change the output torque or speed of a mechanical system.

\section{Sprocket and Chain Transmission}

\section{Shaft and Bearing}

A shaft is a rotating device that is used for the transmission of power while A bearing is a machine element that constrains relative motion to only the desired motion, and reduces friction between moving parts.

\section{Methods}

\section{Rack and Pinion Mechanism}

Speed breaker power generator converters is basically a new concept of non-conventional energy generation. It is an electro-mechanical energy generating machine. This machine converts reciprocating motion in to rotary motion but for the purpose of this project we consider only the translational motion of the mechanism. Here first important point is how we get the translational motion, which is prime input in the system. For that we use weight of Moving vehicle on the Speed breaker. We put our machine underneath the Speed breaker installing different units. The head of rack is brought up to level beneath the speed breaker surface. When vehicle moves on the speed breaker, the rack will be pushed downward. The rack is attached with free wheel type pinion that rotates in one direction only. The rack \& pinion arrangement convert reciprocating motion in to rotary motion. A "generator" and "motor" is essentially the same thing: what you call it depends on whether electricity is going into the unit or coming out of it. A generator produces electricity. In a generator, something causes the shaft and armature to spin. This generated ac power passes through a bridge rectifier whereby the rectifier rectify into dc which charges and discharges the smooth capacitor and flow to the load/output (. The drawing of the designed speed breaker power generator is as shown in Figure 7

\section{RESULTS AND DISCUSSION}

\section{Determination of the Spring Constant}

The spring constant is the slope of the graph and was gotten to be:

$K=3266.67 \mathrm{~N} / \mathrm{m}$

Estimation of the Maximum Torque that can be generated by the system:

$\tau=\operatorname{Fr} \sin \theta$

Where $\theta$ is the angle made between the rack and Pinion

$F$ is the force required to give the spring the maximum depression

$r$ is the adius of the pinion 
$F=k e F=3266.67 \times 0.1062 F=346.92 N \tau=346.92 \times 0.019 \sin 90 \tau=6.591 \mathrm{Nm}$

\section{Estimation of the Maximum Revolution Per Minute (RPM)}

The diameter of the Pinion $=0.037 \mathrm{mThe}$ maximum depression of the Rack $=0.1062$

One trip of the rack is equivalent to 2.87revolutions of the piniion

For both the front and back tyres of a car moving through the speed bump we have that

Number of Revolutions $=2.87 \times 4=11.48$

For one minute we obtain RPM $=2028.81 R P M$

Estimation of the Maximum Power that can be harvested from the designed system.

Maximum Power $(h p)=\frac{\text { Torque } \times R P M}{5252}=\frac{6.59 \times 2028.81}{5252}=2.55 h p=1.90 \mathrm{~kW}$

The Maximum Power Output $=1.90 \mathrm{~kW}$

\section{DISCUSSION}

From this research, up to $1.90 \mathrm{KW}$ of power was able to be generated from the speed bump power generator constructed, Ramadan etal.,(2015) carried out a similar research and were able to generate a maximum of $0.56 \mathrm{KW}$ of power from the constructed speed bump power generator. It is worthy of note that one of the factors responsible for the variation in output power is the spring constant of the choice spring used in the research.

The Power output is more than sufficient to light up street lights, road signs, Phone charging outlets and perform many other functions that do not require very heavy power.

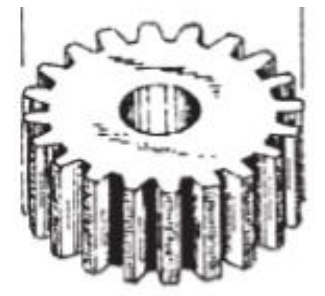

Figure1. Gear

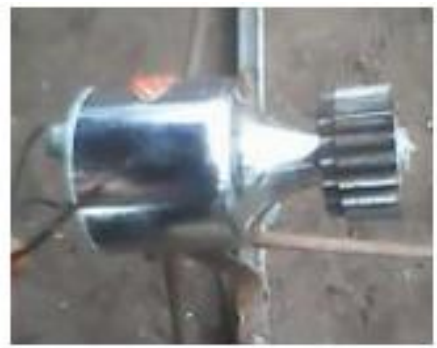

Figure4. Electrical Generator

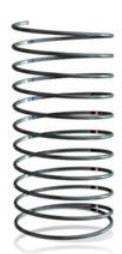

Figure2. Compression Spring

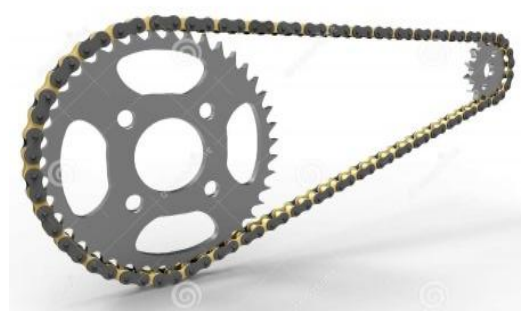

Figure5. Chain and Sprocket

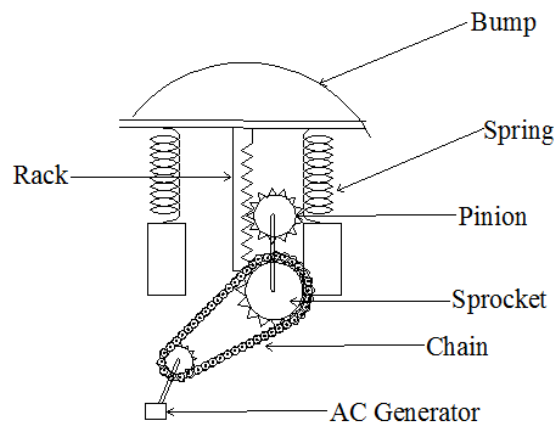

Figure7. Speed breaker power generator

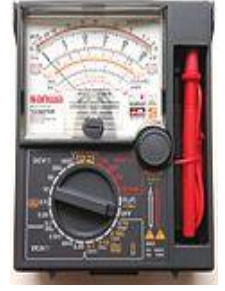

Figure3. Multimeter

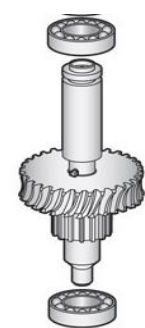

Figure6. Shaft and Bearing 
Table1. Depression of spring with Applied Mass

\begin{tabular}{|l|c|c|c|c|}
\hline S/No. & Mass $(\mathbf{K g})$ & Force $(\mathbf{N})$ & Length $(\mathbf{m})$ & Depression d = lo $-\mathbf{l}(\mathbf{m})$ \\
\hline 1. & 5.00 & 49.00 & 0.110 & 0.030 \\
\hline 2. & 10.00 & 98.00 & 0.094 & 0.040 \\
\hline 3. & 15.00 & 147.00 & 0.076 & 0.060 \\
\hline 4. & 20.00 & 196.00 & 0.058 & 0.080 \\
\hline 5. & 25.00 & 245.00 & 0.047 & 0.090 \\
\hline
\end{tabular}

Table2. Summary of Results

\begin{tabular}{|l|l|}
\hline Parameters determined & Values \\
\hline Spring Constant (k) & $3266.6 \mathrm{~N} / \mathrm{m}$ \\
\hline Maximum torque (T) & $6.59 \mathrm{~N} / \mathrm{m}$ \\
\hline Maximum Revolution per Minute (RPM) & $2028.81 \mathrm{RPM}$ \\
\hline Maximum Power (hp) & $1.90 \mathrm{KW}$ \\
\hline
\end{tabular}

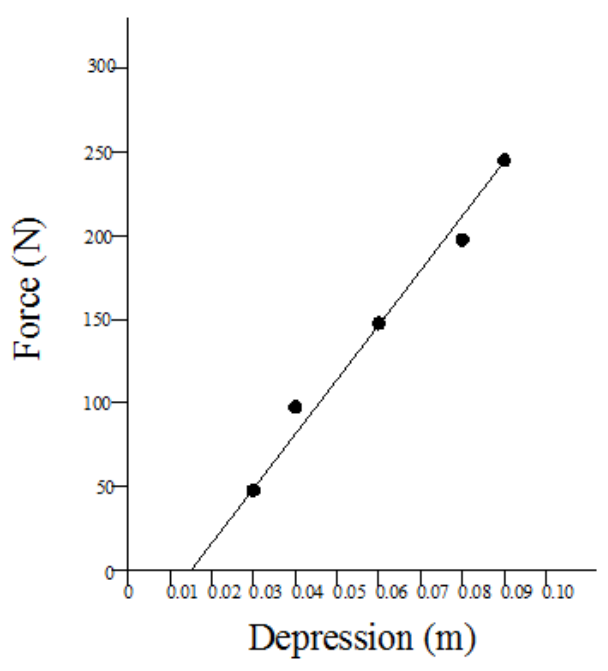

\section{Conclusion}

Implementation of the Power generating speed bumps should be encouraged in heavy traffic roads round the country to harvest electrical Power from moving cars. In its own little way, it will be able to reduce the electricity demand on the national grid.

\section{ACKNOWLEDGEMENT}

The authors acknowledge the Department of Pure and Applied Physics of Federal University Wukari and the Department of Physics of Nasarawa State University Keffi for allowing us access to their physics laboratories to perform experiments.

\section{REFERENCES}

[1] Schlabbach, K., Traffic Calming in Europe. ITE, 1997: p. 38-40.

[2] Rozenblat, L. How Generator Work. 2008 [cited 2012 April 5]; Available from: http://www. generato rguide. net/howgeneratorworks.html

[3] The Encyclopedia Americana; a library of universal knowledge (1918), New York: Encyclopedia Americana Corp

[4] Shi, L.S., Yit Lin Chew, M.,(2012). A review on sustainable design of renewable energy systems. Renewable Sstainable Energy Review, 16:192-207

[5] Panwar, N.L., Kaushik, S.C., Kothari, S. (2011) Role of renewable energy sources in environmental protection. Renewable Sustainable Energy Review, 15: 1753-1766

[6] Solangi, K.H., Islam M.R., Saidur R, Rahim, N.A, Fayaz, H. (2011). A review on global solar energy policy. Renewable Sustainable Energy Review, 15:2149-2163

[7] Joselin- Hebert, G.M., Iniyan, S., Sreevalsan, E., Rajapandian, S. (2007). A review of wind energy technology. Renewable Sustainable Energy Review, 11:1117-1145 
[8] Ramadan, M., Khaled, M., Hachem, F, Alshaer, A., Chaline, K, Assi, A. (2013). A design and analysis of an HVAC-Based Heat recovery system. International Conference on Microelectronics, ICM, 2103. Special Issue on Renewable Energy, Beirut, Lebanon.

[9] Gupta, A., Chaudhary, K., Agrawal, B.N. (2012). An experimental study of generation of electricity using speed breaker. International Journal of Mechanical Engineering, 1:35-40.

Citation: Iyen, C.et al. (2017). Design and Construction of a Speed Bump Power Generator, International Journal of Innovative Research in Electronics and Communications (IJIREC), 4(2), pp.1-5, DOI: http:// dx.doi.org/10.20431/2349-4050.0402001

Copyright: (C) 2017 Iyen, C. This is an open-access article distributed under the terms of the Creative Commons Attribution License, which permits unrestricted use, distribution, and reproduction in any medium, provided the original author and source are credited 